NBER WORKING PAPER SERIES

\title{
WORLD SHOCKS, WORLD PRICES, AND BUSINESS CYCLES: AN EMPIRICAL INVESTIGATION
}

\author{
Andrés Fernández \\ Stephanie Schmitt-Grohé \\ Martín Uribe \\ Working Paper 22833 \\ http://www.nber.org/papers/w22833 \\ NATIONAL BUREAU OF ECONOMIC RESEARCH \\ 1050 Massachusetts Avenue \\ Cambridge, MA 02138 \\ November 2016
}

We would like to thank Laura Alfaro, Ivan Petrella, and the participants at the International Seminar on Macroeconomics held in Sofia, Bulgaria, June 24-25, 2016 for comments. Santiago Tellez-Alzate provided excellent research assistance. The views expressed herein are those of the authors and do not necessarily reflect the views of the National Bureau of Economic Research.

NBER working papers are circulated for discussion and comment purposes. They have not been peer-reviewed or been subject to the review by the NBER Board of Directors that accompanies official NBER publications.

(C) 2016 by Andrés Fernández, Stephanie Schmitt-Grohé, and Martín Uribe. All rights reserved. Short sections of text, not to exceed two paragraphs, may be quoted without explicit permission provided that full credit, including $(\odot$ notice, is given to the source. 
World Shocks, World Prices, and Business Cycles: An Empirical Investigation Andrés Fernández, Stephanie Schmitt-Grohé, and Martín Uribe

NBER Working Paper No. 22833

November 2016

JEL No. F41

\section{ABSTRACT}

Most existing studies of the macroeconomic effects of global shocks assume that they are mediated by a single intratemporal relative price such as the terms of trade and possibly an intertemporal price such as the world interest rate. This paper presents an empirical framework in which multiple commodity prices and the world interest rate transmit world disturbances. Estimates on a panel of 138 countries over the period 1960-2015 indicate that world shocks explain on average 33 percent of aggregate fluctuations in individual economies. This figure doubles when the model is estimated on post 2000 data. The increase is attributable mainly to a change in the domestic transmission mechanism as opposed to changes in the world commodity price process as argued in the literature on the financialization of world commodity markets.

Andrés Fernández

Research Department

Inter-American Development Bank

1300 New York Avenue NW

Washington DC 20577

andresf@iadb.org

Stephanie Schmitt-Grohé

Department of Economics

Columbia University

420 West 118th Street, MC 3308

New York, NY 10027

and NBER

stephanie.schmittgrohe@columbia.edu
Martín Uribe

Department of Economics

Columbia University

International Affairs Building

New York, NY 10027

and NBER

martin.uribe@columbia.edu

A data appendix is available at http://www.nber.org/data-appendix/w22833

A Replication Files is available at http://www.columbia.edu/ mu2166/fsu/index.htm 


\section{Introduction}

The conventional wisdom is that world shocks mediated by the terms of trade represent a major source of aggregate fluctuations in both developed and developing countries. This view is to a large extent based on the predictions of calibrated open economy real business-cycle models (Mendoza, 1995; Kose, 2002). However, recent empirical work based on structural vector autoregression models suggests that world shocks mediated by the terms of trade alone explain on average only 10 percent of variations in output and other indicators of aggregate activity in poor and emerging countries (Schmitt-Grohé and Uribe, 2015). These authors argue that the terms of trade may be a poor mediator of world shocks because being a single summary measure of world prices they may fail to capture the role of individual prices in transmitting global disturbances. Indeed in model economies with multiple goods, a single world price is in general insufficient to capture the transmission mechanism of world shocks to the domestic economy.

This paper presents an empirical model in which multiple world prices mediate the effects of global shocks on domestic business cycles. Specifically, it estimates the joint contribution of agricultural, metal, and fuel commodity prices and the world interest rate to aggregate fluctuations in a panel of 138 countries over the period 1960 to 2015. The empirical model consists of a foreign bloc and a domestic bloc. The foreign bloc is common to all countries and includes the three commodity prices and the world interest rate. The domestic bloc is country specific and includes four domestic macroeconomic indicators, output, consumption, investment, and the trade balance, and the four world prices featured in the foreign bloc.

We find that world shocks account for about one third of movements in aggregate activity in the median country. This number is three times as large as those obtained in single world price specifications. An additional contribution of the present paper is to correct for a smallsample bias in the variance decomposition. We find that the small sample bias is large, about twelve percentage points of the share of the variance of domestic macroeconomic indicators explained by world shocks. Thus the uncorrected measure of the contribution of world shocks, which is the appropriate statistic for comparison with the existing literature, is 45 percent.

A natural question is whether for each individual country a single commodity price transmits the majority of the effects of world shocks. For example, is the price of metals the primary transmitter of world shocks to Chile, or the price of fuel the primary transmitter of world shocks to Norway? We find that this is not the case. For the typical country one commodity price is important for transmitting world shocks to one macroeconomic indicator but not to other indicators. For example, for a given country metal prices can be impor- 
tant for transmitting world shocks to domestic output whereas agricultural prices might be important for transmitting world shocks to domestic consumption. An implication of this finding is that a multiple price specification is needed to capture the transmission of world shocks even if the exports or imports of a country are highly concentrated in a particular commodity.

The period elapsed since the turn of the century has been special as far as world shocks are concerned for two reasons. First, the period witnessed the greatest global contraction since the Great Depression of the 1930s. Second, world commodity markets have experienced enormous financial innovation, a phenomenon that has come to be known as financialization. With this motivation in mind, we ask whether during this period world shocks were particularly important in driving domestic business cycles, and if so, how much of the difference is due to the financialization of commodity markets. To this end, we begin by estimating the model post 2000. We find that during this period world shocks explain on average 79 percent of the variance of output. This is 46 percentage points more than in the 1960 to 2015 sample. This finding is consistent with Fernández, González, and Rodríguez (2015), who estimate that a country-specific commodity price measure explains about 50 percent of aggregate fluctuations in Brazil, Chile, Colombia, and Peru over the period 2000 to 2014. It is also consistent with the findings of Shousha (2015), who documents that in a group of advanced and emerging commodity exporters world price shocks played a major role in driving short-run fluctuations since the mid 1990s.

To investigate how much of the increased importance of world shocks may be accounted for by the financialization of commodity markets, we conduct a counterfactual exercise in which the stochastic process for world prices (the foreign bloc) is fit to the post 2000 period but the domestic bloc of the empirical model is fit over the whole sample. We find that only ten percentage points of the estimated 45 percentage points increase in the importance of global shocks since the 2000s is due to a change in the stochastic process of world prices. We interpret this result as suggesting that financialization has not played a major role in the observed increased importance of world disturbances in domestic business cycles post 2000.

The remainder of the paper is organized as follows. Section 2 describes the data set. Section 3 presents summary statistics of the commodity price data. Sections 4 and 5 introduce the foreign and domestic blocs of the empirical model, respectively. Section 6 describes the small-sample bias correction procedure. Section 7 shows estimation results for the case in which world shocks are mediated by commodity prices, and section 8 for the case in which they are mediated in addition by world interest rate shocks. Section 9 considers the case in which world output enters the foreign bloc either by itself or in conjunction with world commodity prices. Section 10 compares the results of the baseline estimation to 
the case in which the foreign bloc consists of a single world price. Section 11 analyzes the robustness of the main findings. Section 12 investigates the financialization hypothesis and section 13 concludes. An online appendix presents some additional robustness results.

\section{The Data}

We use a panel of three world commodity-prices and five country-specific macroeconomic indicators. The sample is annual and covers the period 1960-2014 for 138 countries.

Data on commodity prices come from the World Bank's Pink Sheet. This is a publicly available dataset that contains monthly series on dollar-denominated nominal commodity price indices (see http://www.worldbank.org/en/research/commodity-markets). We focus on three aggregate commodity price indices: Fuel, Agriculture, and Metals and Minerals. The fuel index is a weighted average of spot prices of coal, crude oil and natural gas. The agricultural index is a weighted average of prices of beverages (cocoa, coffee and tea), food (fats and oils, grains, and other foods), and agricultural raw materials (timber and other raw materials). The price index of metals and minerals is based on the spot prices of aluminum, copper, iron ore, lead, nickel, steel, tin, and zinc. We interpret all other goods as a composite, whose price is proxied by the U.S. consumer price index. We use this composite good as the numeraire. Accordingly, we deflate the three commodity-price indices by the monthly U.S. Consumer Price Index. To obtain annual time series, we take simple averages over the twelve months of the year.

The five country-specific series are real GDP (denoted $Y$ ), real consumption (denoted $C$ ), real investment (denoted $I$ ), the trade balance-to-output ratio (denoted $T B Y$ ), and the terms of trade (denoted TOT). The terms of trade are the ratio of trade-weighted export and import unit-value indices. We use the terms of trade to compare multiple-world-price models with single-world-price models. The series $Y, C$, and $I$ are in constant local currency units. The sources for $Y, C, I, T B Y$, and TOT are the World Bank's World Development Indicators (WDI) database and the IMF's World Economic Outlook (WEO) database. We do not mix WDI and WEO data at the country level. Instead, for each country, we use data from the data set that contains the longest balanced panel for the five country-specific indicators. If the range happens to be identical in the two, we use WDI as the default. The WDI database is publicly available on the web at http://data.worldbank.org. The WEO database is also publicly available but not for all time series. To complete the WEO data we use an appendix of the WEO that the IMF shares with other multilateral organizations. We discard countries for which no balanced panel can be formed of a minimum of 25 annual observations. This delivers a sample of 138 countries. The mean country sample spans 38 
years from 1977 to 2014. The longest sample contains 55 years from 1960 to 2014 and occurs in 5 countries. The shortest sample contains 25 years and occurs in 7 countries.

The data used in this paper is available online with the rest of the replication materials. Table 1 in the online appendix provides country-by-country information about data ranges and sources.

\section{Commodity Prices: Some Empirical Regularities}

The left panel of figure 1 displays the level of the real price of three groups of commodities, agricultural, fuels, and metals. All prices are deflated using the U.S. CPI index, and normalized to $1960=1$. The three commodity price indices share some common characteristics. In the early 1970s agricultural and fuel prices increased dramatically, with fuel prices rising eightfold. Metal prices, however, remained more or less stable. In the 1980s and 1990s, the prices of all three commodities were in a gradual decline. Both agricultural and fuel prices fell by a factor of 4 and metals by a factor of about 3. Then, in the early 2000s all three prices recovered vigorously until the Great Contraction of 2008, which was accompanied by widespread declines in commodity prices.

The right panel of figure 1 displays the cyclical component of the natural logarithm of commodity prices as captured by the HP filter with a smoothing parameter of 100 . Two characteristics stand out. First, the cyclical components of real commodity prices are highly volatile, especially those of fuels, with deviations from trend of up to 50 percent. Second, the cyclical components display positive comovement. These features are confirmed in table 1, which shows second moments of the detrended commodity prices. The standard deviation of prices ranges from 12 to 21 percent making commodity prices between 3 and 5 times as volatile as output in the average country in our sample of 138 countries. Positive comovement between the three price indices is reflected in high and positive contemporaneous correlations of 0.35 to 0.59 . Finally, cyclical movements in commodity prices are moderately persistent, with a serial correlation of about 0.5 .

\section{The Foreign Bloc}

We assume that world commodity prices are exogenous to each individual country. We therefore formulate a VAR specification for the joint evolution of agricultural, fuel, and metal commodity prices that is independent of domestic macroeconomic indicators in individual 
Figure 1: Real Commodity Prices: Level and Cyclical Component, 1960-2014
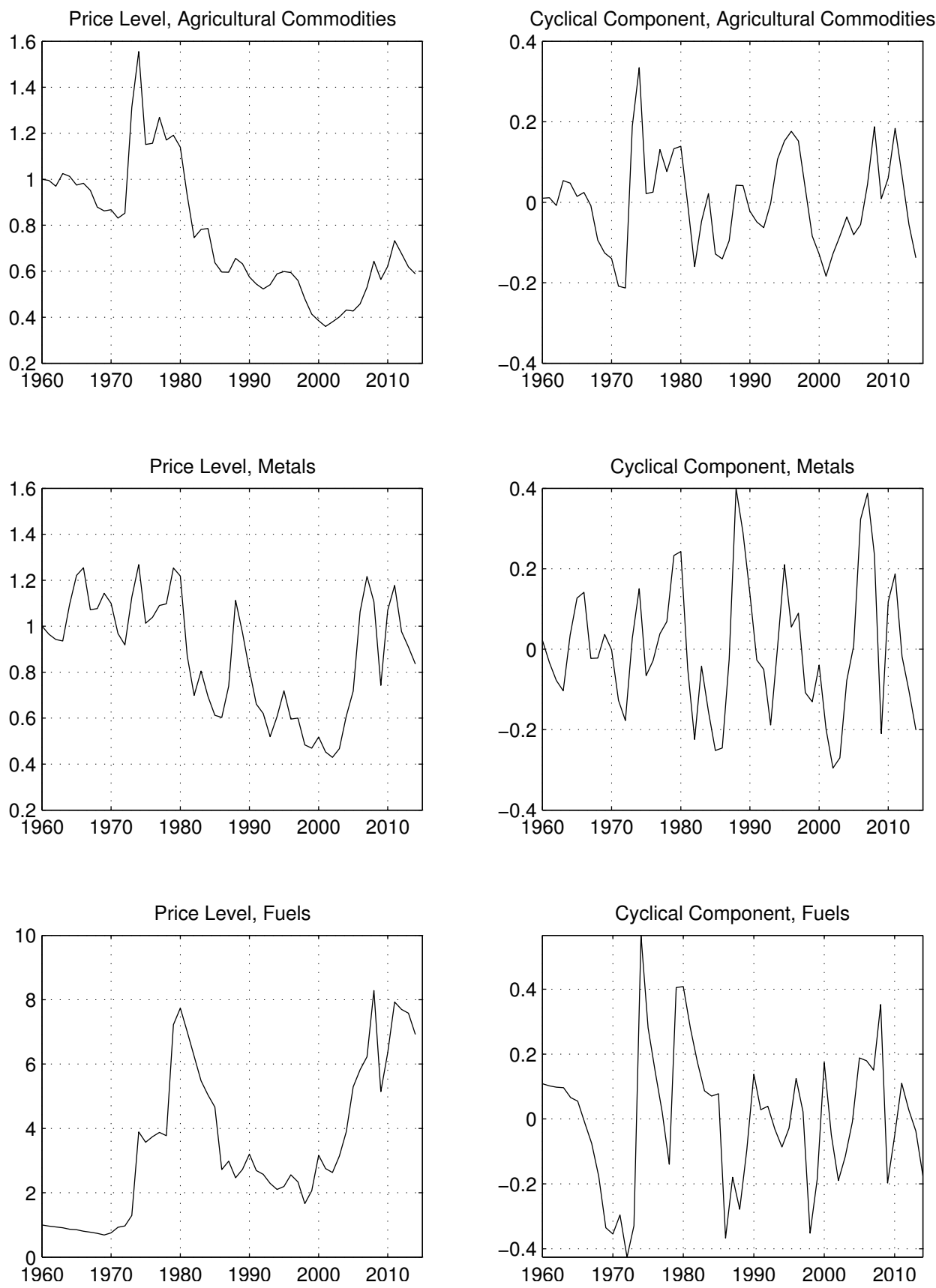

Note. The three left panels displays the level of U.S. dollar commodity price indices deflated by the U.S. consumer price index normalized to $1960=1$. The three right panels displays the cyclical components of these series. The cyclical component is obtained by HP 100 filtering the data. Replication file levels1.m in fsu.zip 
Table 1: World Prices: Second Moments of Cyclical Components

\begin{tabular}{lrrrr}
\hline \hline Statistic & $p^{a}$ & $p^{m}$ & $p^{f}$ & $r$ \\
\hline Standard Deviation, $\sigma(p)$ & 0.12 & 0.17 & 0.21 & 0.01 \\
Serial Correlation, $\rho(p)$ & 0.57 & 0.52 & 0.47 & 0.36 \\
Correlation with Agri., $\rho\left(p^{a}, p\right)$ & 1.00 & 0.59 & 0.49 & -0.01 \\
Correlation with Metals, $\rho\left(p^{m}, p\right)$ & 0.59 & 1.00 & 0.35 & 0.16 \\
Correlation with Fuels, $\rho\left(p^{f}, p\right)$ & 0.49 & 0.35 & 1.00 & -0.24 \\
Correlation with Interest Rate, $\rho(r, p)$ & -0.01 & 0.16 & -0.24 & 1.00 \\
Relative Std.Dev, $\sigma(p) / \sigma(G D P)$ & 2.70 & 3.92 & 4.99 & 0.32 \\
\hline \hline
\end{tabular}

Note. The three commodity prices are deflated by the U.S. CPI index. The variable $r$ denotes the real interest rate and is defined as the difference between the threemonths Treasury bill rate and the U.S. CPI inflation rate (for details, see section 8). All real commodity prices and the gross real interest rate are logged and HP filtered with smoothing parameter 100. The relative standard deviation with respect to GDP is an average over the 138 countries in the sample. Annual data from 1960 to 2014. Replication file levels1.m in fsu.zip

countries. Formally, let

$$
p_{t}=\left[\begin{array}{c}
p_{t}^{a} \\
p_{t}^{f} \\
p_{t}^{m}
\end{array}\right],
$$

where $p_{t}^{a}, p_{t}^{f}$, and $p_{t}^{m}$ denote the cyclical component of the natural logarithm of real world prices of agricultural, fuel, and metal commodities, respectively, detrended using the HP filter with a smoothing parameter of 100 . We assume that $p_{t}$ evolves according to the following first-order autoregressive system:

$$
p_{t}=A p_{t-1}+\mu_{t}
$$

where $A$ denotes a matrix of coefficients and $\mu_{t}$ is an i.i.d. mean-zero random vector with variance-covariance matrix $\Sigma_{\mu}$.

We interpret the vector $\mu_{t}$ as representing a combination of world shocks affecting commodity prices. The present investigation is not concerned with the identification of specific world shocks (such as, for example, shocks to the world supply or demand of oil, or shocks to world total factor productivity). Instead, our focus is to ascertain what fraction of business-cycle fluctuations in individual countries is due to world shocks and is mediated by fluctuations in the three world commodity prices included in the vector $p_{t}$. That is, we are interested in estimating the joint contribution of $\mu_{t}$ to domestic business cycles in individual 
countries. For this purpose, no further identification assumptions on the above system are required. In particular, the order in which the three commodity prices appear in the vector $p_{t}$ is immaterial. Any other ordering would deliver identical contributions of world shocks to domestic business cycles.

We estimate the foreign bloc, given by equation (1), by ordinary least squares (OLS) equation by equation using annual data from 1960 to 2014. The estimates of the matrices $A$ and $\Sigma_{\mu}$ are: ${ }^{1}$

$$
\begin{gathered}
A=\left[\begin{array}{rrr}
0.64 & -0.14 & 0.07 \\
0.58 & 0.29 & 0.11 \\
0.03 & -0.21 & 0.61
\end{array}\right], \quad \Sigma_{\mu}=\left[\begin{array}{lll}
0.0084 & 0.0063 & 0.0073 \\
0.0063 & 0.0312 & 0.0091 \\
0.0073 & 0.0091 & 0.0190
\end{array}\right] \\
R^{2}=\left[\begin{array}{lll}
0.38 & 0.32 & 0.33
\end{array}\right]
\end{gathered}
$$

The $R^{2}$ statistics indicate that about two thirds of movements in commodity prices are explained by contemporaneous disturbances and the remaining one third by the autoregressive component.

\section{The Domestic Bloc}

Let $Y_{t}^{i}$ denote a vector of domestic macroeconomic indicators in country $i$. We assume that $Y_{t}^{i}$ evolves according to the expression

$$
Y_{t}^{i}=B^{i} p_{t-1}+C^{i} Y_{t-1}^{i}+D^{i} p_{t}+\epsilon_{t}^{i}
$$

where $\epsilon_{t}^{i}$ is an innovation with mean 0 and variance-covariance matrix $\Sigma_{\epsilon}^{i}$. Note that because $p_{t}$ appears contemporaneously on the right-hand side of this expression, the innovation $\epsilon_{t}^{i}$ is independent of the innovation $\mu_{t}$. We interpret $\epsilon_{t}^{i}$ as a vector of country-specific shocks. This interpretation is based on the fact that the typical country in our sample of 138 countries is a small economy. As such, world shocks can affect the small open economy only through changes in world prices, such as changes in commodity prices or changes in the world interest rate. For now, we leave the world interest rate out of the system, but will consider it in section 8 below.

We estimate the domestic bloc, equation (2), by OLS for each of the 138 countries in the sample. We consider four domestic macroeconomic indicators, output, consumption, investment, and the trade-balance-to-output ratio. All variables are detrended using the

\footnotetext{
${ }^{1}$ Replication file est_sequential.m in fsu.zip, objects A, Sigma_mu, and R2p.
} 
HP filter with a smoothing parameter of 100. Output, consumption and investment are expressed in natural logarithms before detrending. We denote by $y_{t}^{i}, c_{t}^{i}, i_{t}^{i}$, and $t b y_{t}^{i}$ the cyclical components of output, consumption, investment, and the trade-balance-to-output ratio in country $i$ as defined above.

Combining equations (1) and (2) and dropping for expositional purposes the superscript $i$, we obtain the following autoregressive representation for the joint behavior of $p_{t}$ and $Y_{t}$

$$
\left[\begin{array}{l}
p_{t} \\
Y_{t}
\end{array}\right]=F\left[\begin{array}{l}
p_{t-1} \\
Y_{t-1}
\end{array}\right]+G\left[\begin{array}{l}
\mu_{t} \\
\epsilon_{t}
\end{array}\right]
$$

where

$$
F=\left[\begin{array}{ll}
A & \emptyset \\
D A+B & C
\end{array}\right], \quad G=\left[\begin{array}{ll}
I & \emptyset \\
D & I
\end{array}\right], \quad \text { and } \quad E\left[\begin{array}{ll}
\mu_{t} \mu_{t}^{\prime} & \mu_{t} \epsilon_{t}^{\prime} \\
\epsilon_{t} \mu_{t}^{\prime} & \epsilon_{t} \epsilon_{t}^{\prime}
\end{array}\right]=\Sigma \equiv\left[\begin{array}{ll}
\Sigma_{\mu} & \emptyset \\
\emptyset & \Sigma_{\epsilon}
\end{array}\right] \text {. }
$$

Given country-specific estimates of $B, C, D$, and $\Sigma_{\epsilon}$, one can use this representation to obtain an estimate of the contribution of world shocks $\left(\mu_{t}\right)$ to movements in domestic macroeconomic indicators $\left(Y_{t}\right)$ in a specific country by performing a variance decomposition.

Given the heterogeneity in the lengths of the balanced samples, not all country specific regressions display the same number of degrees of freedom. Specifically, when all four domestic macroeconomic indicators $\left(y_{t}, c_{t}, i_{t}\right.$, and $\left.t b y_{t}\right)$ are included in the vector $Y_{t}$, each equation of the domestic bloc contains 11 regressors, namely, 3 contemporaneous commodity prices, 3 lagged commodity prices, 4 lagged domestic indicators, and a constant (not shown in the derivations above). Since the number of observations for the domestic bloc ranges from 25 to 55 across the 138 countries, we have that for some countries including 11 regressors results in a relatively small number of degrees of freedom.

For this reason, we estimate the domestic bloc in two ways. One is to include all four indicators in the vector $Y_{t}$, which imposes the maximum strain on the degrees of freedom. The other is to include in $Y_{t}$ only one domestic indicator at the time and estimate the domestic bloc four times per country, once for each indicator. We refer to the first approach as joint estimation and to the second as sequential estimation.

\section{Small-Sample Bias Correction}

A second issue that must be taken into account in the estimation of the SVAR system (3) is the possibility of a small-sample upward bias in the estimation of the contribution of world shocks to the variance of domestic macroeconomic indicators. The fact that the variance is by 
definition a positive statistic means that any correlation between the vector of commodity prices $p_{t}$ and the vector of macroeconomic indicators $Y_{t}$ results in some participation of world shocks in the variance of $Y_{t}$. In particular, even if $p_{t}$ and $Y_{t}$ were independent random variables, any spurious correlation (positive or negative) in finite sample would result in a positive share of world shocks in the variance of $Y_{t}$, creating an upward bias that exaggerates the importance of world shocks mediated by commodity prices.

In addition, as is well known, OLS estimates of SVAR coefficients are typically biased in short sample, which can cause a bias in the estimated contribution of world shocks to domestic business cycles. This bias can be increasing in the number of commodities entering $p_{t}$ and decreasing in the sample size. Correcting this source of bias is therefore particularly important when one compares one-price SVAR specifications (e.g., specifications including only one world price), which we study in a later section, with multiple-price specifications, like the one studied thus far.

We apply a Monte Carlo procedure to correct for the aforementioned small-sample biases. The procedure consists of the following steps:

1. For a given country, let $\hat{F}, \hat{G}$, and $\hat{\Sigma}$ denote the estimates of $F, G$, and $\Sigma$ obtained using actual data. Let $\hat{\sigma}$ denote the associated estimate of the share of the variance of $Y_{t}$ explained by $\mu_{t}$. Use $\hat{F}, \hat{G}$, and $\hat{\Sigma}$ to generate artificial time series for $Y_{t}$ and $p_{t}$ of a desired length from the SVAR model given in equation (3). We use 250 years.

2. Let $T^{p}$ denote the sample size of commodity prices. We set $T^{p}=55$, which is the sample size of commodity prices in our data set. Let $T^{y}$ denote the sample size of $Y_{t}$. We set $T^{y}$ equal to the number of observations of $Y_{t}$ in our dataset for the particular country considered. Then use the last $T^{p}$ observations of the artificial time series to reestimate the foreign bloc of the SVAR (i.e., the matrices $A$ and $\Sigma_{\mu}$ ). Use the last $T^{y}$ observations of the artificial time series to reestimate the domestic bloc (i.e., the matrices $B, C, D$, and $\left.\Sigma_{\epsilon}\right)$.

3. Steps 1 and 2 yield an estimate of the matrices $F, G$, and $\Sigma$ from the simulated data. Use this estimate to compute the share of the variance of $Y_{t}$ explained by $\mu_{t}$ shocks, which is denoted by $\sigma$.

4. Repeat steps 1-3 $N$ times. We set $N=1,000$. Then compute averages of the resulting estimate of $\sigma$ and denote it by $\bar{\sigma}$.

5. Define the small-sample bias as $\bar{\sigma}-\hat{\sigma}$. The corrected estimate of the share of the variance of $Y_{t}$ explained by $\mu_{t}$ is then given by $2 \hat{\sigma}-\bar{\sigma}$. 
Table 2: Share of Variances Explained by World Shocks and Mediated by Commodity Prices

\begin{tabular}{lcccc}
\hline \hline & \multicolumn{4}{c}{ Cross Country Median } \\
& of Variance Share \\
& $y$ & $c$ & $i$ & $t b y$ \\
\hline Sequential Estimation & & & & \\
Noncorrected Estimate & 0.44 & 0.34 & 0.34 & 0.29 \\
Small-Sample Bias & 0.10 & 0.13 & 0.12 & 0.13 \\
Corrected Estimate & 0.34 & 0.21 & 0.21 & 0.15 \\
MAD of Corrected Estimate & 0.20 & 0.17 & 0.19 & 0.17 \\
\hline Joint Estimation & & & & \\
Noncorrected Estimate & 0.46 & 0.37 & 0.39 & 0.35 \\
Small-Sample Bias & 0.11 & 0.13 & 0.13 & 0.14 \\
Corrected Estimate & 0.35 & 0.25 & 0.26 & 0.22 \\
MAD of Corrected Estimate & 0.21 & 0.19 & 0.20 & 0.17 \\
\hline \hline
\end{tabular}

Note. Variance decompositions based country-by-country estimates of the SVAR system (3) and (4). MAD stands for the cross-country median absolute deviation. Statistics are computed across 138 countries. Sequential estimation refers to the case that the vector $Y_{t}$ of domestic variables contains only one of the four domestic variables, $y_{t}, c_{t}, i_{t}$, or $t b y_{t}$. Joint estimation refers to the case in which $Y_{t}$ contains all four domestic indicators. Country-specific results are in the replication code and in the online appendix. Replication files bias_sequential_run.m and bias_joint_run.m in fsu.zip.

6. Perform steps 1 through 5 for each of the 138 countries in the panel.

\section{World Shocks Mediated By Commodity Prices}

In this section we perform variance decompositions country by country using the estimated SVAR system, equation (3), to assess the importance of world shocks as a driver of domestic business cycles. We present results for the sequential and joint estimation approach and variance decompositions with and without the small-sample bias correction.

Table 2 contains the main results. It displays cross-country median shares of the variances of output, consumption, investment, and the trade-balance-to-output ratio explained by world shocks mediated by commodity prices. Both the sequential and joint estimation approaches deliver the same message. Before correcting for small-sample bias, across countries on average world shocks are estimated to explain 44 percent of business cycle fluctuations in domestic output. For all four domestic indicators the small-sample bias in the variance 
decomposition is on average about 12 percentage points. After correcting for the smallsample bias, we find that world shocks explain about 34 percent of variance of output, 21 percent of the variances of consumption and investment, and 15 percent of the variance of the trade-balance-to-output ratio.

The estimated contribution of world shocks, however, is far from homogeneous across countries. Table 2 shows that the cross-country median absolute deviation of the share of the variance of output explained by world shocks is 20 percentage points. This means that across countries most of the estimated variance shares lie in an interval ranging from 14 to 54 percent. This interval includes the high and low values found in the related literature cited in the introduction.

\section{World Shocks Mediated By The World Interest Rate and Commodity Prices}

The world interest rate represents another channel through which world shocks are transmitted to open economies. Unlike real commodity prices, which represent the relative price of goods dated in the same period, the real interest rate is the relative price of goods dated in different periods. World shocks that change the global availability of goods across time will cause movements in the world real interest rate. In turn, movements in the world interest rate affect incentives to consume, save, and work at the individual-country level. This argument motivates adding the real interest rate to the set of world prices that mediate world shocks to individual countries.

Accordingly, we expand the foreign bloc of the SVAR system, equation (1), by including the world interest rate in the vector of world prices. Formally, we now let

$$
p_{t}=\left[\begin{array}{c}
p_{t}^{a} \\
p_{t}^{f} \\
p_{t}^{m} \\
r_{t}
\end{array}\right]
$$

where $r_{t}$ denotes the real world interest rate in period $t$. The domestic bloc of the SVAR is unchanged.

We proxy $r_{t}$ by the real three-month U.S. Treasury bill rate. Specifically, we compute monthly real interest rates by subtracting from the annualized Treasury bill rate the U.S. CPI inflation rate over the previous twelve months. We then compute the annual real interest rate as the arithmetic average of the monthly rates for each year. The sample period for this 
variable is the same as that of world commodity prices, namely, 1960 to 2014 . We extract the cyclical component of the world real interest rate by applying the HP filter with parameter 100 to the logarithm of the gross world real interest rate. Table 1 shows that the world interest rate is mildly persistent (serial correlation of 0.36 ), uncorrelated with agricultural prices (-0.01), mildly positively correlated with metal prices (0.16), and negatively correlated with fuel prices $(-0.24)$.

The OLS estimates of the matrices $A$ and $\Sigma_{\mu}$ defining the expanded foreign bloc are: ${ }^{2}$

$$
\begin{gathered}
A=\left[\begin{array}{rrrr}
0.64 & -0.14 & 0.08 & -0.08 \\
0.58 & 0.35 & 0.04 & 3.01 \\
0.03 & -0.21 & 0.60 & 0.36 \\
-0.02 & -0.01 & -0.00 & 0.31
\end{array}\right], \quad \Sigma_{\mu}=\left[\begin{array}{rrrr}
0.0084 & 0.0063 & 0.0073 & 0.0002 \\
0.0063 & 0.0297 & 0.0089 & -0.0002 \\
0.0073 & 0.0089 & 0.0190 & 0.0003 \\
0.0002 & -0.0002 & 0.0003 & 0.0001
\end{array}\right], \\
R^{2}=\left[\begin{array}{llll}
0.38 & 0.35 & 0.33 & 0.24
\end{array}\right] .
\end{gathered}
$$

The interest rate adds little explanatory power to the commodity price sub-bloc, as indicated by the insignificant increase in the $R^{2}$ statistics associated with the first three equations after adding $r_{t}$ as a regressor. Furthermore, much of the variation in the real interest rate is driven by contemporaneous disturbances, with the autoregressive part explaining only 24 percent of the variance of the interest rate (the $R^{2}$ of the fourth equation).

Table 3 presents the shares of the variances of domestic macroeconomic indicators explained by world shocks mediated by the world interest rate and commodity prices. Including the interest rate as an additional transmission channel increases the share of world shocks in the variance of domestic variables by about 10 percentage points. This finding holds for both the sequential and joint estimation. Thus, overall world shocks explain more than 40 percent of the variance of output and more than 30 percent of the variances of consumption, investment, and the trade-balance-to-output ratio.

\section{World Shocks Transmitted Via World Output}

In some specifications of theoretical open economy models, it is assumed that the country faces a world demand for a domestically produced tradable good. The foreign demand function is typically ad-hoc and incorporates as arguments the relative price of the good and global output. This assumption presupposes that the country has some market power in the production of the tradable good in question. In most cases, a foreign demand function of this type is introduced to facilitate the modeling of price stickiness in tradable goods. Under

\footnotetext{
${ }^{2}$ Replication file est_sequential_r.m in fsu.zip, objects A, Sigma_mu, and R2p.
} 
Table 3: Share of Variances Explained by World Shocks and Mediated by Commodity Prices and the World Interest Rate

\begin{tabular}{lcccc}
\hline \hline & \multicolumn{4}{c}{ Cross Country Median } \\
& $y$ & $c$ & $i$ & $t b y$ \\
\hline Sequential Estimation & & & & \\
Noncorrected Estimate & 0.55 & 0.44 & 0.45 & 0.37 \\
Small-Sample Bias & 0.10 & 0.13 & 0.13 & 0.15 \\
Corrected Estimate & 0.44 & 0.31 & 0.33 & 0.23 \\
MAD of Corrected Estimate & 0.18 & 0.20 & 0.19 & 0.19 \\
\hline Joint Estimation & & & & \\
Noncorrected Estimate & 0.56 & 0.50 & 0.50 & 0.46 \\
Small-Sample Bias & 0.11 & 0.14 & 0.14 & 0.15 \\
Corrected Estimate & 0.43 & 0.37 & 0.34 & 0.31 \\
MAD of Corrected Estimate & 0.19 & 0.20 & 0.20 & 0.19 \\
\hline \hline
\end{tabular}

Note. Variance decompositions based country-by-country estimates of the SVAR system (3) and (4). MAD stands for the cross-country median absolute deviation. Statistics are computed across 138 countries. Sequential estimation refers to the case that the vector $Y_{t}$ of domestic variables contains only one of the four domestic variables, $y_{t}$, $c_{t}, i_{t}$, or tbyt. Joint estimation refers to the case in which $Y_{t}$ contains all four domestic indicators. Replication files bias_sequential_r_run.m and bias_joint_r_run.m in fsu.zip. 
Table 4: Share of Variances Explained by World Shocks and Mediated by Commodity Prices and Global Output

\begin{tabular}{lllll}
\hline \hline & \multicolumn{4}{c}{ Cross Country Median } \\
& $y$ & $c$ & $i$ & of \\
& 0.34 & 0.21 & 0.21 & 0.15 \\
\hline A. Baseline & 0.20 & 0.17 & 0.19 & 0.17 \\
MAD & 0.44 & 0.31 & 0.33 & 0.23 \\
B. Baseline Plus Interest Rate & 0.18 & 0.20 & 0.19 & 0.19 \\
MAD & 0.45 & 0.29 & 0.34 & 0.26 \\
C. Baseline Plus Global Output & 0.18 & 0.14 & 0.16 & 0.14 \\
MAD & 0.12 & 0.06 & 0.11 & 0.01 \\
D. Only Global Output & 0.13 & 0.08 & 0.15 & 0.07 \\
$\quad$ MAD &
\end{tabular}

Note. The data is annual and the estimation of the domestic bloc is sequential. Variance shares are corrected for small sample bias. Panels A and B are reproduced from tables 2 and 3, respectively.

this specification, world shocks can affect the domestic economy directly through variations in global output. Here, we entertain this possibility by adding global output to the baseline specification of the foreign bloc of the SVAR model. That is, we now consider a four variable foreign bloc that includes the three commodity prices (agriculture, fuel, and metal) and global output.

We construct global GDP as the sum of GDP in current U.S. dollars of the 29 largest economies in the panel deflated by the U.S. consumer price index. We then estimate the domestic block sequentially for each of the remaining 109 countries in the panel and correct for small sample bias.

The results of adding global output are shown in table 4. As in the case of the world interest rate, adding one more global variable to the foreign bloc increases the share of variances of domestic macro indicators explained by world shocks by about 10 percentage points (panels A, B, and C). Notably, the inclusion of global output does not alter the effect of global shocks on the domestic economy mediated by world commodity prices. This follows from the fact that adding global output to the baseline specification increases the variance explained by world shocks by the same amount as the fraction of variance explained by world shocks in a specification of the foreign bloc that includes only global output (compare panels C and D). 
Table 5: Share of Variances Explained by World Shocks in One-Price Specifications

\begin{tabular}{lllll}
\hline \hline & \multicolumn{4}{c}{ Cross Country Median } \\
& of Variance Share \\
Model Specification & $y$ & $c$ & $i$ & $t b y$ \\
\hline 1. Four World Prices, $p^{a}, p^{f}, p^{m}, r$ & 0.44 & 0.31 & 0.33 & 0.23 \\
2. One World Price, $p^{a}$ & 0.08 & 0.02 & 0.02 & 0.09 \\
3. One World Price, $p^{f}$ & 0.09 & 0.03 & 0.03 & 0.11 \\
4. One World Price, $p^{m}$ & 0.10 & 0.01 & 0.05 & 0.06 \\
5. One World Price, $r$ & 0.03 & 0.01 & 0.01 & 0.01 \\
6. Best Single World Price for $y$ & 0.27 & 0.06 & 0.09 & 0.08 \\
7. First Principal Component of $p^{a}, p^{f}, p^{m}, r$ & 0.05 & 0.03 & 0.04 & 0.04 \\
8. Terms of Trade, tot $_{t}$ & 0.06 & 0.06 & 0.04 & 0.08 \\
9. Commodity Terms of Trade & 0.08 & 0.05 & 0.03 & 0.01 \\
\hline \hline
\end{tabular}

Note. The domestic bloc is estimated sequentially. Statistics are medians across 138 countries, corrected for small-sample bias. Line 1 is reproduced from table 3. Replication files located in fsu.zip: lines 2-6, bias_sequential_one_p_run.m; line 7, bias_sequential_pc_run.m; line 8, bias_sequential_tot_run.m; line 9, bias_sequential_pcom3_run.m.

\section{One-World-Price Specifications}

Often, open economy models, empirical or theoretical, include just one world price, typically the terms of trade. In a recent study, Schmitt-Grohé and Uribe (2015) emphasize that SVAR models that include only the terms of trade in the foreign bloc predict that the terms of trade have a limited ability to transmit world shocks and recommend the use of more disaggregated world price measures. In this section, we extend this result by considering a host of single-price measures of world prices and ask whether empirically the inclusion of only one world price suffices to transmit the bulk of the effects of world shocks to domestic economies. Our findings suggest that the answer to this question is no. Thus, the result that a single world price measure is insufficient to transmit world shocks holds not only when the single price is taken to be the terms of trade but also for a variety of other single world price measures.

The results presented in this section are based on a sequential estimation of the domestic bloc and are corrected for small-sample bias. We begin by including, one at a time, each of the four world prices that appear in the foreign bloc estimated in section 8, namely, agricultural, metal, and fuel commodity prices, and the world interest rate. Lines 2 to 5 of table 5 show that when only one world price is included in the SVAR, world shocks are estimated to explain on average across countries less than 10 percent of the variances of 
output, consumption, investment, and the trade-balance-to-output ratio.

It might come as a surprise that fuel prices, which are often regarded as a major source of aggregate fluctuations, transmit only 9 percent of the effects of world shocks on domestic activity. This finding, however, is consistent with other SVAR-based studies that have analyzed the importance of, for instance, oil price shocks. For example, Blanchard and Galí (2010) report using U.S. data over the periods 1960 to 1983 and 1984 to 2007 that the ratio of the standard deviation of output conditional on oil price shocks relative to its unconditional counterpart is 0.33 on average, which implies a variance share of around 10 percent.

The finding that single-world-price specifications are inadequate to capture the transmission of world shocks to the domestic economy is intuitive, for it is not reasonable to expect that the same world price will be equally effective in transmitting world shocks to all economies. For instance, an economy in which metals do not play an important role either in production or in absorption is unlikely to be affected by world shocks that are mostly mediated through metal prices.

One might therefore think that a more reasonable specification of a one-world-price empirical model would be one that picks for each country the single world price that transmits world shocks explaining the largest fraction of output fluctuations at business-cycle frequency. Line 6 of table 5 shows that when the best transmitter of world shocks is picked for each country, the estimated share of the variance of output explained by world shocks is 27 percent, still lower than but much closer to 44 percent, the fraction transmitted jointly by all four world prices (see Line 1, reproduced from table 3). However, the best transmitter of world shocks to output is not the best transmitter of world shocks to the other macroeconomic indicators. The fraction of the variances of consumption, investment, and the trade-balance-to-output ratio explained by the world shocks transmitted by the best transmitter to output is still below 10 percent on average across countries (line 6). This means that not all world prices affect all macroeconomic indicators in the same way. This is reasonable. For instance, in an economy that produces fuels and imports agricultural goods, the world shocks that affect mostly oil prices are likely to have a larger effect on output than on consumption. This result suggests that a multiple world-price SVAR specification conveys much more information than models that include only one world price.

The result that one-world-price specifications do not capture well the transmission mechanism of world shocks to individual economies extends to one-world-price measures that are combinations of multiple world prices. Lines 7, 8, and 9 of table 5 show that the estimated share of the variances of all four macroeconomic indicators considered (output, consumption, investment, and the trade-balance-to-output ratio) is below 10 percent when the single world-price measure takes the form of the first principal component of the four world prices 
considered $\left(p^{a}, p^{f}, p^{m}\right.$, and $\left.r\right)$, the terms of trade, or a commodity terms of trade measure. The terms of trade and the commodity terms of trade are country-specific relative price indicators. The terms of trade is the ratio of trade weighted export to import price indices. The commodity terms of trade is the ratio of commodity export prices to commodity import prices. In turn, commodity export prices are defined as a trade weighted average of the three commodity prices considered in this paper (agricultural, metal, and fuel) with the weights given by the respective country specific commodity export shares. A similar definition applies to commodity import prices. The result that terms of trade mediate a small fraction of world shocks is in line with that emphasized by Schmitt-Grohé and Uribe (2015), who find that terms of trade shocks explain about 10 percent of the variances of output, consumption, investment, and the trade balance across 38 poor and emerging countries. Here, we extend this result to 138 countries, including rich, emerging, and poor.

\section{Robustness}

In this section, we extend the analysis to control for a number of factors that may affect the importance of world prices as transmitters of world disturbances. In particular, we control for the level of development, country size, whether the country is a large commodity exporter, whether the country is an oil exporter, whether the country is a commodity exporter or importer, geographic location, and detrending method. All of the extensions are based on the baseline SVAR specification that includes three world prices, namely, agricultural, fuel, and metal commodity prices. The estimation of the domestic bloc is performed sequentially, and variance decompositions are corrected for small sample bias.

\subsection{Level of Development}

A priori it is not clear how the level of development should affect the importance of world shocks as drivers of domestic business cycles. On the one hand, one may expect that developed countries, by having more service oriented economies, and hence a larger share of nontradables, are less exposed to world shocks. On the other hand, developed countries, especially small ones, tend to be more integrated to the rest of the world, which would suggest a larger exposure to world shocks.

To gauge the role of world shocks as a source of business cycles at different levels of economic development, panel A of Table 6 displays results for four income levels: low (22 countries), lower middle (33 countries), upper middle (31 countries), and high (52 coun-

tries). The categorization is taken from the WDI and is based on per capita gross national 
incomes observed in 2015. ${ }^{3}$ The results are fairly robust across income groups. There are no clear differences in the share of output variance explained by world shocks across income groups and no single group is radically different from the baseline median results, which are reproduced for convenience in the top line of table 6 . In particular, there is no systematic relation between income levels and the share of the variances of output or the trade balance explained by world shocks. For consumption and investment, there is some positive relationship between the level of development and the share of variance accounted for by world shocks. The strongest relationship is for investment. The share of the variance of this variable explained by world shocks increases from 14 percent in low income countries to 30 percent in high income countries.

\subsection{Country Size}

The identifying assumption in the baseline SVAR specification is that world prices are exogenous to the domestic economy. This assumption is reasonable for most countries, but may be problematic for some. One example is large economies. In these countries, domestic shocks may affect world prices. For this reason, it is of interest to examine the predictions of the model after controlling for country size. To this end, we divide the 138 countries in the panel into quintiles according to their GDP in 2013 measured in U.S. dollars. This yields five groups of about 27 countries each. ${ }^{4}$ The results are displayed in panel B of table 6 .

The results are fairly robust across groups other than the top quintile. For these four groups, the shares of variance of output, consumption, investment, and the trade balance explained by world shocks are close to the unconditional medians reported at the top of the table. However, as conjectured above, we find a sizable difference for the group of largest economies. Within this group, world shocks are found to be more important than for the median country in the panel of 138 countries. For the median largest country world shocks explain 42 percent of the variance of output and investment, 29 percent of the variance of consumption, and 26 percent of the variance of the trade-balance-to-output ratio. Thus the contribution of world shocks to the variance of domestic variables increases by about 10 percentage points in the group of largest countries relative to the unconditional contribution. As stressed above, however, this result should not be interpreted as indicating that world shocks are more important for large economies, because the exogeneity assumption upon which the SVAR model relies does not apply for countries that can affect world prices.

In the online appendix, we also consider a demographic definition of country size. Again, we divide countries into quintiles. As in the output-based definition of size, the contribution

\footnotetext{
${ }^{3}$ The results are robust to basing the categorization on income levels in 1990, see the online appendix.

${ }^{4}$ We drop Syria and Taiwan due to lack of data for GDP in U.S. dollars in 2013.
} 
Table 6: Robustness

\begin{tabular}{|c|c|c|c|c|c|c|}
\hline \multirow[b]{2}{*}{ Model Specification } & \multirow{2}{*}{$\begin{array}{l}\text { Number of } \\
\text { Countries }\end{array}$} & \multirow{2}{*}{$\begin{array}{l}\text { Share of } \\
\text { Countries }\end{array}$} & \multicolumn{4}{|c|}{ Share of Variance } \\
\hline & & & $y$ & $c$ & $i$ & tby \\
\hline Baseline & 138 & 100 & 0.34 & 0.21 & 0.21 & 0.15 \\
\hline \multicolumn{7}{|l|}{ A. Level of Development } \\
\hline - Low Income & 22 & 15.9 & 0.23 & 0.18 & 0.14 & 0.24 \\
\hline - Lower Middle Income & 33 & 23.9 & 0.37 & 0.19 & 0.17 & 0.16 \\
\hline - Upper Middle Income & 31 & 22.5 & 0.25 & 0.21 & 0.22 & 0.23 \\
\hline - High Income & 52 & 37.7 & 0.34 & 0.24 & 0.30 & 0.13 \\
\hline \multicolumn{7}{|l|}{ B. Country Size } \\
\hline - First Quintile (smallest) & 27 & 19.6 & 0.34 & 0.18 & 0.17 & 0.11 \\
\hline - Second Quintile & 27 & 19.6 & 0.25 & 0.11 & 0.16 & 0.16 \\
\hline - Third Quintile & 28 & 20.3 & 0.29 & 0.23 & 0.20 & 0.15 \\
\hline - Fourth Quintile & 28 & 20.3 & 0.27 & 0.23 & 0.21 & 0.16 \\
\hline - Fifth Quintile (largest) & 26 & 18.8 & 0.42 & 0.29 & 0.42 & 0.26 \\
\hline \multicolumn{7}{|l|}{ C. Excluding Large } \\
\hline Commodity Exporters & 99 & 72 & 0.32 & 0.20 & 0.18 & 0.15 \\
\hline \multicolumn{7}{|l|}{ D. Oil } \\
\hline - Exporters & 27 & 19.6 & 0.36 & 0.22 & 0.22 & 0.28 \\
\hline - Importers & 107 & 77.5 & 0.33 & 0.21 & 0.20 & 0.15 \\
\hline \multicolumn{7}{|l|}{ E. Net Commodity Trader } \\
\hline - Exporters & 51 & 37.0 & 0.25 & 0.21 & 0.18 & 0.18 \\
\hline - Importers & 83 & 60.1 & 0.36 & 0.22 & 0.27 & 0.15 \\
\hline \multicolumn{7}{|l|}{ F. Geographic Region } \\
\hline - East Asia and Pacific & 17 & 12.0 & 0.32 & 0.21 & 0.19 & 0.14 \\
\hline - Europe and Central Asia & 30 & 22.0 & 0.37 & 0.26 & 0.24 & 0.10 \\
\hline - Latin America and Caribbean & 24 & 17.0 & 0.43 & 0.22 & 0.27 & 0.15 \\
\hline - Middle East and North Africa & 18 & 13.0 & 0.21 & 0.22 & 0.31 & 0.29 \\
\hline - North America & 2 & 1.0 & 0.30 & 0.34 & 0.32 & 0.52 \\
\hline - South Asia & 5 & 4 & 0.47 & 0.30 & 0.35 & 0.27 \\
\hline - Sub-Saharan Africa & 42 & 30 & 0.32 & 0.15 & 0.17 & 0.20 \\
\hline \multicolumn{7}{|l|}{ G. Data Detrending } \\
\hline - HP Filter $\lambda=6.25$ & 138 & 100.0 & 0.23 & 0.16 & 0.14 & 0.11 \\
\hline - Quadratic Trend & 138 & 100.0 & 0.24 & 0.24 & 0.23 & 0.20 \\
\hline
\end{tabular}

Note. The reported variance shares are group-specific medians. The online appendix provides information about the country composition of each group under the different classifications. The data is annual. The foreign bloc consists of three commodity price indices (agriculture, fuels, and metals). The domestic bloc is estimated sequentially and variance shares are corrected for small sample bias. 
of world shocks is not sensitive to country size, except at the top quintile.

\subsection{Excluding Large Commodity Exporters}

Another often suggested way to address the possibility of market power, which would violate our identification assumption of exogeneity of commodity prices at the country level, is to exclude large commodity exporters. To this end, for each of the three commodity groups we identify the top 20 percent largest exporters. We then exclude the union of these countries from the panel. This criterion yields 39 large commodity exporters, and therefore 99 countries used in the SVAR estimation. Panel $\mathrm{C}$ of table 6 shows that excluding large commodity exporters does not affect the share of the variances of domestic macroeconomic indicators explained by world shocks and mediated by commodity prices.

Taken together, the result of the present robustness test and those performed in the previous subsection suggest that market power in commodities might stem more from country size (as measured by total output or population size) than from the size of commodity exports. This makes economic sense, since market power should be related to a country's share in worldwide production or absorption of a certain commodity rather than to its share in worldwide exports thereof.

\subsection{Oil Exporters and Oil Importers}

In panel D of table 6 we consider categorizing countries according to their net trade in fuel oil. We do so by computing the country-specific median of net exports of fuels since 1960, using annual information on exports and imports of fuel commodities from WDI. We categorize a country as an oil exporter (importer) if the median net fuel export share in GDP is positive (negative). According to this criterion we identify 27 oil exporters and 107 importers. ${ }^{5}$

Results do not differ much between net oil exporters and importers. For the trade balance share, however, the share of its variance explained by world shocks is almost twice as large for oil exporters than it is for oil importers.

\subsection{Net Commodity Trader}

World shocks appear to be more important for explaining business cycles in countries that are net commodity importers than in countries that are net commodity exporters (see panel E of table 6). We define a country as a commodity exporter if it has a positive trade balance in the

\footnotetext{
${ }^{5}$ We drop Angola, Haiti, Myanmar, and Taiwan due to lack of information on the trade shares on commodities.
} 
group of three commodities considered (agricultural, fuel, and metals) on average since 1960. This classification yields 51 net commodity exporters and 83 net commodity importers. ${ }^{6}$ On average the contribution of world shocks to the variances of output and investment is 10 percentage points higher for net commodity importers than for net commodity exporters. No significant differences are observed for consumption and the trade balance. This result might be linked to the fact that investment goods contain a larger share of traded goods than consumption goods.

\subsection{Other Robustness Checks: Geographic Location and Quadratic Detrending}

Table 6 presents two additional robustness checks. Panel F classifies countries by geographic region. The results do not vary much across the different quarters of the world, although world shocks appear to be somewhat more important in explaining output movements in Latin America and South Asia. Panel G shows that using a quadratic time trend or the $\mathrm{HP}(6.25)$ filter instead of the $\mathrm{HP}(100)$ filter to detrend the data does not result in significant differences, except for the variance of output for which the contribution of world shocks falls by 10 percentage points.

\section{Financialization}

Some researchers have pointed to the fact that, since the early 2000s, commodity futures have become a popular asset class for portfolio investors, just like stocks and bonds. This process is sometimes referred to as "financialization" of commodity markets (see Cheng and Xiong, 2014 and the references cited therein). A distinctive characteristic of this process is a large inflow of investment capital to commodity futures markets, generating a debate about whether this distorts commodity prices. We now explore the extent to which financialization of commodity markets has impacted the importance of world shocks for domestic business cycles.

\subsection{The Importance of World Shocks In Quarterly Data}

The analysis of financialization relies heavily on a comparison of data before and after 2004, which makes the use of annual data ill suited, as it would imply estimating the SVAR model with only 10 observations for the latter subsample. For this reason, here we introduce

\footnotetext{
${ }^{6}$ Again, we drop Angola, Haiti, Myanmar, and Taiwan due to lack of information on the trade shares on commodities.
} 
Table 7: Share of the Variance of Output Explained by World Shocks and Mediated by Commodity Prices and the Interest Rate: Quarterly Data

\begin{tabular}{lccc}
\hline \hline & \multicolumn{2}{c}{ Cross Country Median of Variance Share } \\
& $\begin{array}{c}\text { Quarterly } \\
\text { (38 countries) }\end{array}$ & $\begin{array}{c}\text { Annual } \\
\text { (38 countries) }\end{array}$ & $\begin{array}{c}\text { Annual } \\
\text { (138 countries })\end{array}$ \\
\hline Noncorrected Estimate & 0.38 & 0.54 & 0.55 \\
Small-Sample Bias & 0.05 & 0.10 & 0.10 \\
Corrected Estimate & 0.33 & 0.42 & 0.44 \\
MAD of Corrected Estimate & 0.16 & 0.16 & 0.18 \\
\hline \hline
\end{tabular}

Note. The quarterly data is detrended using the $\mathrm{HP}(1600)$ filter. The list of countries in each group is presented in the online appendix. The foreign bloc includes four world prices, namely, the three world commodity prices (agriculture, fuels, and metals) and the world interest rate. Replication file quarterly\compare_annual.m in fsu.zip.

quarterly data. This comes at a cost. On the bright side, quarterly data on commodity prices and interest rates is readily available since 1960. However, quarterly data typically covers a much shorter sample period especially for macroeconomic aggregates other than output. For this reason, we limit attention to SVAR specifications that include output as the sole domestic variable. For a country to be included in our panel, we require at least 100 consecutive quarterly observations. This criterion yields a panel of 38 countries. $^{7}$

Before plunging into the issue of financialization, we examine the robustness of our results to the use of quarterly data. The foreign bloc of the SVAR system includes four world prices, namely, the three world commodity prices (agriculture, fuels, and metals) and the world interest rate. The domestic bloc consists of output. The data are detrended using the HP(1600) filter. Table 7 shows that when estimated on quarterly data the contribution of world shocks to the variance of output is 33 percent. This estimate is sizable and comparable to but lower than its annual counterpart. The annual estimate using the same 38 countries as in the quarterly panel yields an output variance share of world shocks of 42 percent (which in turn is similar to the value obtained using all 138 countries in the annual panel).

\subsection{Commodity Prices Pre- and Post-Financialization}

Existing accounts date commodity financialization around 2004. As a first diagnostic, we examine the comovement and volatility of the cyclical component of commodity prices before and after 2004. The results are shown in table 8. Commodity prices display higher comovement since 2004, especially for commodity price pairs that include fuels prices. The

\footnotetext{
${ }^{7}$ The list of countries is available in the online appendix.
} 
Table 8: Comovement and Volatility of Commodity Prices Pre and Post Financialization

\begin{tabular}{lccc}
\hline \hline & \multicolumn{3}{c}{ Sample Periods } \\
\cline { 2 - 4 } & 1960:Q1- & 1960:Q1- & 2004:Q1- \\
Statistic & $2015: \mathrm{Q} 4$ & 2003:Q4 & $2015: \mathrm{Q} 4$ \\
\hline$\rho\left(p^{a}, p^{f}\right)$ & 0.36 & 0.30 & 0.61 \\
$\rho\left(p^{a}, p^{m}\right)$ & 0.56 & 0.57 & 0.54 \\
$\rho\left(p^{f}, p^{m}\right)$ & 0.42 & 0.33 & 0.65 \\
$\sigma\left(p^{a}\right)$ & 0.08 & 0.08 & 0.08 \\
$\sigma\left(p^{f}\right)$ & 0.17 & 0.17 & 0.19 \\
$\sigma\left(p^{m}\right)$ & 0.14 & 0.13 & 0.18 \\
\hline \hline
\end{tabular}

Note. $p^{a}, p^{f}$, and $p^{m}$ stand for the world prices of agricultural, fuel, and metal commodities, respectively. $\rho$ and $\sigma$ stand for correlation and standard deviation, respectively. All prices are deflated by the U.S. CPI deflator and HP(1600) filtered over the period 1960:Q1 to 2015:Q4. Replication file quartely\compare_corr.m in fsu.zip.

correlation of fuels with both agricultural and metal prices doubles after 2004. Standard deviations increase after 2004 but the change is not as pronounced as that observed for correlations. In particular, the standard deviations of agricultural and fuel prices change little, while that of metal prices increases by 50 percent.

We interpret these results as lending some support to the hypothesis of financialization. The central question for the purpose of the present investigation is whether financialization changed the importance of world shocks in explaining domestic business cycles. We turn to this issue next.

\subsection{Financialization or Change In The Domestic Transmission Mechanism?}

In the context of the SVAR model studied in this paper, we interpret financialization as a change after 2004 in the stochastic process defining the foreign bloc. Specifically, we take financialization to mean that the matrices $A$ and $\Sigma_{\mu}$ in equation (1) changed after 2004. We gauge how the importance of world shocks in driving domestic business cycles changed with financialization by estimating the variance of domestic output explained by world shocks using estimates of the foreign bloc on post 2004 data, while keeping the estimates of the domestic bloc, defined by the matrices $B, C, D$, and $\Sigma_{\epsilon}$ in equation (2), on data over the whole sample, which includes the pre- and post-financialization periods. The results of this analysis is presented in table 9. Comparing the first two rows of this table shows that financialization led to a modest increase in the importance of world shocks for domestic 
Table 9: Financialization and the Variance of Output Explained By World Shocks

\begin{tabular}{lccc}
\hline \hline & \multicolumn{2}{c}{ Estimation Period } & Variance \\
\cline { 2 - 3 } Specification & Foreign bloc & Domestic bloc & Share \\
\hline Baseline & Whole sample & Whole sample & 0.33 \\
Financialization & Post 2003 & Whole sample & 0.42 \\
Post 2003 & Post 2003 & Post 2003 & 0.79 \\
\hline \hline
\end{tabular}

Note. Variance shares are corrected for small sample bias. Replication file quarterly $\backslash$ fin.m in fsu.zip.

business cycles. The cross-country median of the share of the variance of output explained by world shocks increases from 33 percent to 42 percent in the financialization period.

We also explore the possibility that in recent years the domestic bloc changed either because of a change in the domestic transmission mechanism (matrices $B, C$, and $D$ ) or because of the amplitude and correlation of domestic disturbances (the matrix $\Sigma_{\epsilon}$ ). To evaluate this alternative hypothesis, we estimate both the foreign and the domestic blocs on the post 2003 sample. The results, shown in line 3 of table 9 are striking. World shocks explain on average 79 percent of the variance of domestic output in the post 2003 period. This represents 46 percentage points more than in the baseline case (line 1 ). We conclude that world shocks appear to play a major role in recent years. However, this preponderance is not due to the phenomenon of financialization of commodity markets, but to a change in the domestic transition mechanism or in the relative importance of domestic sources of uncertainty or in both.

In closing, a cautionary word is in order. Before concluding that 2004 represents a structural break, as suggested by the dramatic increase in the importance of world shocks for domestic business cycles after 2003, it is important to keep in mind that this result is derived using a short sample, spanning just twelve years. As a result, the conclusions drawn from the present analysis should be interpreted as preliminary pending more incoming data.

\section{Conclusion}

The starting point of this investigation are two observations. First, in theoretical models of small open economies transmission of world shocks must be mediated via variations in world prices, which can be intratemporal relative prices of different types of traded goods or intertemporal prices, such as interest rates. Second, world prices are independent of domestic conditions in the small open economy. These two observations motivate the use of 
an empirical model composed of a foreign bloc and a domestic bloc. The foreign bloc includes only world prices whereas the domestic bloc includes domestic macroeconomic indicators and world prices.

We construct an annual panel of 138 poor, emerging, and rich countries spanning the period 1960 to 2015. The panel includes observations on three world commodity prices (agricultural, fuels, and metals), a proxy for the world interest rate and four country specific macroeconomic indicators (output, consumption, investment, and the trade balance).

The main finding reported in this paper is that global shocks explain a sizable fraction of business cycles. On average across countries more than one third of the variances of output, consumption, investment, and the trade balance are accounted for by world disturbances. This result is robust to using quarterly data.

When the model is estimated using post 2000 data, the importance of world shocks in accounting for domestic business cycles doubles. We consider two alternative hypotheses as potential explanations of this significant increase. One is that the financialization of commodity markets, which took hold in the early 2000s, changed the joint stochastic process of world commodity prices. The second hypothesis is that post 2000 there was a change in the domestic transmission mechanism. We find that the second hypothesis is more consistent with the data. 


\section{References}

Blanchard, Olivier J., and Jordi Galí, "The Macroeconomic Effects of Oil Price Shocks: Why are the 2000s so different from the 1970s?," in in Jordi Galí and Mark J. Gertler, eds., International Dimensions of Monetary Policy, Chicago, IL: University of Chicago Press, 2010, 373-421.

Cheng, Ing-Haw and Wei Xiong, "Financialization of Commodity Markets," Annual Review of Financial Economics 6, 2014, 419-441.

Fernández, Andrés, Andrés González, and Diego Rodríguez, "Sharing a Ride on the Commodities Roller Coaster: Common Factors in Business Cycles of Emerging Economies," IDB-WP No. 640, March 2015.

Kose, M. Ayhan, "Explaining business cycles in small open economies 'How much do world prices matter?'," Journal of International Economics 56, 2002, 299-327.

Lubik, Thomas K., and Wing Leong Teo, "Do World Shocks Drive Domestic Business Cycles? Some Evidence From Structural Estimation," unpublished manuscript Johns Hopkins University, July 2005.

Mendoza, Enrique, "The Terms of Trade, the Real Exchange Rate, and Economic Fluctuations," International Economic Review 36, February 1995, 101-137.

Shousha, Samer, "Macroeconomic Effects of Commodity Booms and Busts," manuscript, Columbia University, October 2015.

Schmitt-Grohé, Stephanie, and Martín Uribe, "How Important Are Terms Of Trade Shocks?," NBER working paper 21253, June 2015. 